\title{
Correlation Of Serum YKL-40 With Anthropometric Measurements And Spirometric Indices Between Healthy Individuals And Asthamatics In A Tertiary Care Hospital
}

\author{
Syeda Nargis Fatima, Fatima Ali Khan, Jawed Iqbal
}

ABSTRACT:

Objective: To correlate serum levels of YKL-40 with anthropometric measurements and spirometric indices between normal individuals and asthmatics.

Methodology: The case control study was conducted in Department of Chest Medicine, JPMC, Karachi from the month of August 2015 till March 2016. The study recruited sixty participants after satisfying the inclusion and exclusion criteria; among those 30 were normal healthy individuals (PEF $>80 \%$ and pulse rate of $60-80$ beats per minutes); while equal were cases of mild to moderate asthma (PEF more than $50 \%$ and pulse rate of $100-120$ beats per minutes) matched for age and gender. Vitallograph compacta and peak flow meter was used for spirometric indices. Moreover, anthropometric measurements were age, gender, weight $(\mathrm{kg})$, height $(\mathrm{m})$ and body mass index $\left(\mathrm{kg} / \mathrm{m}^{2}\right)$. Ykl-40 Elisa kit was used for serum YKL 40 levels. The data was entered and analysed using SPSS version 21 (IBM, Chicago, IL).

Result: In comparison of Spirometric Evaluation (FEV1, FVC, FEV1/FVC\% and PEFR) between control and patients with mild to moderate asthma. significant difference was found in the mean values of FEV1, FVC, FEV1/FVC and PEFR between cases and controls. Significant inverse correlation was found between YKL-40 with FEV1, FVC, FEVI/FVC\% and PEFR among Controls. YKL-40 was found to be significantly correlated with only $\mathrm{FEV}_{1} / \mathrm{FVC}(\%)$ among cases with correlation co-efficient as -0.510 ( -value $<0.004$ ).

Conclusion: There is an inverse correlation between serum YKL-40 levels and spirometric evaluation thus as the inflammation in asthma increases, YKL-40 level upsurges and causes decrease in lung function tests.

Key Word: Asthma, YKL-40, anthropometric, spirometric, FEV1, FVC, PEFR.

INTRODUCTION:

Asthma is a chronic lung disease of airways characterized as bronchial hyper responsiveness and inflammation as main phenomena ${ }^{1-2}$. Asthma is a result of multi factorial interaction in which both genetic and environmental factors plays a major and significant role ${ }^{3-5}$. Factors responsible for triggering or worsening the asthma symptoms including allergens (i.e. mite, dust, pollens etc.), tobacco, exercise and stress ${ }^{6-7}$. The asthmatics mainly complain about cough, wheezing, chest tightness, and difficulty in breathing ${ }^{7}$.

The disease carries high morbidity and has been reported to have a high prevalence around the globe having affected people of all ages ${ }^{8-9}$. Approximately 300 million people are currently suffering from asthma, and it is anticipated that this count will rise up to 400 million by year $2025^{10}$. It has been estimated that the sufferers of asthma in Pakistan are over six million people and its prevalence is estimated to

I Syeda Nargis Fatima,
I Assistant Professor, Physiology,
I Kaheed Mohtarma Benazir Bhutto Medical College, Lyari |
I Iarachi, Email: nisarusmani58@gmail.com
I Satima Ali Khan,
I Jinnar Lecturer, BMSI,
I Jawed Iqbal,
I Assistant Professor, Pathology,
I Karachi Medical and Dental College, Karachi
I Received: 16-03-18
I Accepted: 14-05-18

be $5 \%$ of the total population ${ }^{11}$. Moreover, in Karachi the biggest metropolitan city of Pakistan, about $8-10 \%$ of population which are suffering from long term asthma and approximately every 250th death is the result of severe asthma exacerbations ${ }^{12}$.

Considering the prevalence of asthma, number of hospitalizations, emergency room visits and mortality rate as a result of severe asthma have increased in recent years, researches have been carried out to better understand the pathogenesis, the early diagnosis and clinical efficacy of treatment modalities have been carried out. Since last two decades, global and national initiatives directing on the treatment and prevention of asthma have been established carrying out the same goals described earlier ${ }^{13-14}$. Spirometry is the lung function test of great importance to diagnose asthma and to monitor the effects of treatment. FEV1 (forced expiratory volume in first second) and FVC (forced vital capacity) are the most important measurements can be done from spirometry along with, monitoring the PEFR that is useful in detecting changes in a patient's asthma control on disease severity ${ }^{15-16}$.

YKL-40 is an N-terminal amino acids, and 40 shows its molecular mass, which is in kilodaltons $(\mathrm{KDa})^{17}$. It is a heparin, collagen, and chitin binding plasma glycoprotein which belongs to the chitinase protein family. Serum YKL40 is a quantifiable serum kitinase - like protein, which down/up regulates the innate immune reactions in inflammatory and tissue remodeling conditions, Normal range is below $40 \mathrm{ng} / \mathrm{ml}$ in serum ${ }^{18}$. YKL-40 is now thought 
Correlation Of Serum YKL-40 With Anthropometric Measurements And Spirometric Indices

to be a novel biomarker of severe disease activity in patients having diseases related to the extent of inflammation, pathological tissue remodeling, and ongoing fibrosis ${ }^{18}$. In the present study it was investigated that whether the serum YKL-40 is associated with anthropometric measurements and spirometric indices between healthy and asthmatic individuals.

\section{PATIENTS AND METHODS:}

In the present case control study 60 individuals were recruited in the department of Chest Medicine, Jinnah Post Graduate Medical Centre (JPMC), Karachi from of August 2015 till March 2016. Among those 30 were normal healthy individuals; while equal were cases of mild to moderate asthma matched for age and gender. The normal healthy individuals had PEF $>80 \%$ and pulse rate of $60-80$ beats per minutes while cases with mild to moderate asthma had PEF more than $50 \%$ and pulse rate of $100-120$ beats per minutes. Cases and controls of age 18 to 60 years, of either gender were enrolled. The exclusion criteria followed were recurrent cough not due to asthma, patients of upper airway obstruction, emphysema, airway embolism chronic obstructive pulmonary disease, congestive heart failure, pulmonary embolism, post transplant patients, and having confirmed diagnosis of diabetes and hypertension. Similar exclusion criteria were followed for both cases and controls.

Spirometry was performed to assess the lung functions by vitallograph compacta. Forced expiratory volume (L) in first second, forced vital capacity (L) and ratio of forced expiratory volume to forced vital capacity was determined by vitallograph and peak expiratory flow rate (L/ min) was determined by conventional peak flow meter. Moreover, 5 cc of blood was drawn from cubital vein of all the enrolled subjects by using aseptic techniques and serum level of YKL-40 was determined through Elisa kit. Importantly, the anthropometric measurements i.e. age, gender, weight (kg), height $(\mathrm{m})$ and body mass index $\left(\mathrm{kg} / \mathrm{m}^{2}\right)$ were recorded on a pre-designed proforma.

For the present study ethical approval was granted by the ethical committee of BMSI, JPMC, Karachi, Pakistan for conducting the research. Written informed consent was obtained from all participants prior to recruitment having explained comprehensively the process involved and benefits/ risks of being the part this research. It was ensured that anonymity and confidentiality of enrolled participant's data was maintained throughout the research and no unauthorized person had an access to the data.

The data was entered and analysed using SPSS version 21 (IBM, Chicago, IL). The data was validated twice for incorrect entries. The quantitative variables were presented as mean \pm standard deviation, while the qualitative variables were presented as frequency/ percentage. The anthropometric measurements i.e. age, weight (kg), height (m) and body mass index $\left(\mathrm{kg} / \mathrm{m}^{2}\right)$ were compared between cases and controls using independent $\mathrm{t}$ - test. Moreover, chi square was used to compare proportion of gender between cases and controls. Furthermore, the $\mathrm{FEV}_{1}(\mathrm{~L}), \mathrm{FVC}(\mathrm{L})$, ratio of $\mathrm{FEV}_{1} / \mathrm{FVC}(\%)$ and PEFR (L/min) and serum YKL levels were also compared between cases and controls. Importantly, separately the correlation was performed for both cases and controls between serum YKL-40 with anthropometric and spirometric evaluations. For all inferential statistics, the pvalue $<0.05$ was considered significant.

\section{RESULTS:}

The table 1 gives details of the comparison of anthropometric measurements between controls and cases. Among anthropometric measurements (age, weight, height and body mass index) significant difference was only found in height between the two groups. Cases with mild to moderate asthma had significantly higher mean height as compared to controls (1.63 Vs. 1.67; p-value $=0.025)$. Moreover, significant difference in proportion of family history of asthma was also found between controls and cases (20\% vs. 56.7\%; pvalue $=0.007)$. Significant difference was found in the mean values of FEV1 $(2.19 \pm 0.5$ Vs. $1.76 \pm 0.79$; p-value $=$ $0.013)$, FVC (2.51 \pm 0.57 Vs. $2.15 \pm 0.62$; p-value $=0.022)$, FEV1/FVC (88.41 \pm 7.17 Vs. $69.92 \pm 9.99 ;$ p-value $=0.001)$ and PEFR (327.83 \pm 80.52 Vs. $198.00 \pm 60.14$; p-value $=$ $0.001)$ between control and cases.

The table 2 gives details of the correlation of YKL-40 and spirometric evaluations (FEV1, FVC, FEV1/FVC\% and PEFR) among controls. None of the anthropometric measurements (age, weight, height and body mass index) were significantly correlated with YKL-40. However, among controls YKL-40 was found to be significantly correlated with the following spirometric parameters $\mathrm{FEV}_{1}(\mathrm{~L}), \mathrm{FEV}_{1} /$ FVC (\%) and PEFR (L/min). The correlation between YKL40 and FEV1 was negative with correlation co-efficient as -0.565 (p-value $<0.001$ ). The correlation between YKL40 and $\mathrm{FEV} 1 / \mathrm{FVC} \%$ was negative with correlation coefficient as $-0.408(\mathrm{p}$-value $=0.025)$. The correlation between YKL-40 and PEFR was negative with correlation co-efficient as -0.633 (p-value $<0.001$ )

The table 3 gives details of the correlation of YKL-40 and spirometric evaluations (FEV1, FVC, FEV1/FVC\% and PEFR) among cases (patients with mild to moderate asthma). The YKL-40 was not found significantly correlated with any of the anthropometric measurements (age, weight, and body mass index) except height. The correlation between YKL-40 and height (m) was positive with correlation coefficient as 0.404 ( $\mathrm{p}$-value $<0.027$ ). However, among spirometric parameters YKL-40 was found to be significantly correlated with only $\mathrm{FEV}_{1} / \mathrm{FVC}(\%)$. The correlation between YKL-40 and $\mathrm{FEV}_{1} / \mathrm{FVC}(\%)$ was negative with correlation co-efficient as -0.510 ( $\mathrm{p}$-value $<0.004)$.

\section{DISCUSSION:}

The present study conducted that aimed to identify whether 
Syeda Nargis Fatima, Fatima Ali Khan, Jawed Iqbal

\begin{tabular}{|c|c|c|c|}
\hline $\begin{array}{l}\text { Anthropometric and } \\
\text { Spirometric parameters }\end{array}$ & $\begin{array}{cl} & \begin{array}{l}\text { Controls } \\
(\mathrm{n}=30)\end{array} \\
\mathbf{n}(\%) & \text { OR Mean } \pm \mathrm{SD}\end{array}$ & \begin{tabular}{|l}
\multicolumn{1}{c|}{ Cases } \\
$(n=30)$ \\
$n(\%)$ OR Mean \pm SD
\end{tabular} & P-value \\
\hline Age (years) & $36.87 \pm 7.87$ & $39.10 \pm 13.09$ & 0.427 \\
\hline $\begin{array}{l}\text { Gender } \\
\text { - Male } \\
\text { - Female }\end{array}$ & $\begin{array}{l}12(40) \\
18(60)\end{array}$ & $\begin{array}{l}11(36.7) \\
19(63.3)\end{array}$ & 0.791 \\
\hline Weight $(\mathrm{Kg})$ & $65.13 \pm 10.40$ & $70.33 \pm 14.04$ & 0.108 \\
\hline Height (meters) & $1.63 \pm 0.05$ & $1.67 \pm 0.09$ & $0.025^{*}$ \\
\hline Body Mass Index $\left(\mathrm{Kg} / \mathrm{m}^{2}\right)$ & $24.51 \pm 3.79$ & $24.90 \pm 3.53$ & 0.687 \\
\hline $\begin{array}{l}\text { Family History of Asthma } \\
-\quad \text { Yes } \\
-\quad \text { No }\end{array}$ & $\begin{array}{l}6(20) \\
24(80)\end{array}$ & $\begin{array}{l}17(56.7) \\
13(43.3)\end{array}$ & $0.007 * *$ \\
\hline $\mathrm{FEV}_{1}(\mathrm{~L})$ & $2.19 \pm 0.50$ & $1.76 \pm 0.79$ & $0.013^{*}$ \\
\hline $\mathrm{FVC}(\mathrm{L})$ & $2.51 \pm 0.57$ & $2.14 \pm 0.62$ & $0.022 *$ \\
\hline $\mathrm{FEV}_{1} / \mathrm{FVC}(\%)$ & $88.40 \pm 7.17$ & $69.92 \pm 9.99$ & $0.001 * *$ \\
\hline PEFR (L/min) & $327.83 \pm 80.52$ & $198.00 \pm 60.14$ & $0.001 * *$ \\
\hline
\end{tabular}

Table 1. Comparison of anthropometric measurements and spirometric evaluations between controls and cases (Mild to moderate asthmatic patients)

\begin{tabular}{|l|c|l|}
\hline $\begin{array}{c}\text { Anthropometric and } \\
\text { Spirometric parameters }\end{array}$ & $\begin{array}{c}\text { Correlation } \\
\text { co-efficient }\end{array}$ & P-value \\
\hline Age (years) & 0.115 & 0.546 \\
\hline Weight $(\mathrm{Kg})$ & -0.231 & 0.219 \\
\hline Height (meters) & -0.288 & 0.122 \\
\hline Body Mass Index $\left(\mathrm{Kg} / \mathrm{m}^{2}\right)$ & -0.137 & 0.472 \\
\hline FEV $_{1}(\mathrm{~L})$ & -0.565 & $0.001 * *$ \\
\hline FVC (L) & -0.322 & 0.082 \\
\hline FEV $/$ FVC $(\%)$ & -0.408 & $0.025^{*}$ \\
\hline PEFR (L/min) & -0.663 & $0.001 * *$ \\
\hline
\end{tabular}

Table 2. Correlation of YKL-40 with anthropometric measurements and spirometric evaluation among controls

the serum YKL-40 is associated with anthropometric measurements and spirometric indices between healthy controls and asthmatic individuals considered as cases. The results of the present study highlighted that cases with mild to moderate asthma had significantly higher mean level as compared to controls. There was significant difference between mean values of spirometric evaluations $\mathrm{FEV}_{1}(\mathrm{~L})$, $\mathrm{FVC}(\mathrm{L})$, ratio of $\mathrm{FEV}_{1} / \mathrm{FVC} \mathrm{( \% )} \mathrm{and} \mathrm{PEFR} \mathrm{(L/min)} \mathrm{between}$ controls and cases. Moreover, among controls YKL-40 was found to be significantly correlated with the following spirometric parameters $\mathrm{FEV}_{1}(\mathrm{~L}), \mathrm{FEV}_{1} / \mathrm{FVC}(\%)$ and PEFR (L/min). Importantly, positive correlation was identified between YKL-40 and height $(\mathrm{m})$ and YKL-40 was negatively correlated with $\mathrm{FEV}_{1} / \mathrm{FVC}(\%)$ with correlation co-efficient

\begin{tabular}{|l|c|l|}
\hline $\begin{array}{c}\text { Anthropometric and } \\
\text { Spirometric parameters }\end{array}$ & $\begin{array}{c}\text { Correlation } \\
\text { co-efficient }\end{array}$ & P-value \\
\hline Age (years) & 0.164 & 0.386 \\
\hline Weight $(\mathrm{Kg})$ & 0.329 & 0.076 \\
\hline Height (meters) & 0.404 & $0.027^{*}$ \\
\hline${\text { Body Mass Index }\left(\mathrm{Kg} / \mathrm{m}^{2}\right)}^{2}$ & 0.138 & 0.468 \\
\hline FEV $_{1}(\mathrm{~L})$ & -0.287 & 0.124 \\
\hline FVC $(\mathrm{L})$ & -0.238 & 0.205 \\
\hline FEV 1 FVC $(\%)$ & -0.510 & $0.004 * *$ \\
\hline PEFR (L/min) & -0.344 & 0.063 \\
\hline
\end{tabular}

Table 3. Correlation of YKL-40 with anthropometric measurements and spirometric evaluation among cases (Mild to moderate asthmatic patients)

as -0.510 among cases.

Asthma is a disease, which is not only significant in terms of morbidity, mortality and quality of life of the patient being affected but also places an economic burden on scarce health resources ${ }^{19-20}$. This disease has multidimensional aspects and asthma exacerbation impact both patients and their families ${ }^{21}$.

The present study also reported the significant difference in the mean FEV1, FVC, FEV1/FVC and PEFR between control and cases. Similar results were reported by Saba et al. (2014) showing significant difference in FEV1, FEV1/FVC between control and asthmatics ${ }^{22}$. Another study reported a decrease in the FEV1/FVC ratio as asthma severity increase ${ }^{23}$. A study also reported that severe asthma 
Correlation Of Serum YKL-40 With Anthropometric Measurements And Spirometric Indices

exacerbation may result in an accelerated loss of pulmonary function as patients who frequently experienced asthma exacerbation showed a greater annual decline in FEV1 than those with infrequent exacerbations ${ }^{24}$.

In the present study conducted we observed significant negative correlation between YKL-40 with FEV1, FEV1/FVC and PEFR in asthmatics ${ }^{25}$. The study conducted by Duru et al. (2013) also showed significant negative correlation between YKL-40 and FEV1, FEV1/FVC. ${ }^{25}$ Another study reported a significant negative correlation between YKL-40 and PEFR among asthmatic patients ${ }^{26}$.

The study has certain limitations. Firstly, the patients with severe asthma were not enrolled as it was not possible to perform spirometric evaluations due to critical health conditions. Secondly, it was difficult to find patients having asthma (cases) without any additional diseases. Thirdly, the present case control study had limited sample size with thirty cases and controls. Increasing the sample size would increase the generalisibility of the research findings.

\section{CONCLUSION:}

The study concluded that there is an inverse correlation between serum YKL-40 levels and spirometric evaluation; $\mathrm{FEV}_{1}(\mathrm{~L}), \mathrm{FEV}_{1} / \mathrm{FVC}(\%)$ and PEFR (L/min) showing that, as the inflammation in asthma increases, YKL-40 level upsurges and causes decrease in lung function tests.

\section{REFERENCES:}

1. Sin DD, Miravitlles M, Mannino DM, Soriano JB, Price D, Celli BR, et al. What is asthma?COPD overlap syndrome? Towards a consensus definition from a round table discussion. Eur Respir J 2016; 48(3):664-73.

2. Wu D, Zhang M, Song Q. Definition of inflammatory subtypes of chronic rhinosinusitis with nasal polyp and asthma. Lin Chung Er Bi Yan Hou Tou Jing Wai Ke Za Zhi 2015; 29(16):1495-1500.

3. Wark PAB, Murphy V, Mattes J. The interaction between mother and fetus and the development of allergic asthma. Expert Rev Respir Med 2014; 8(1):57-66.

4. Collison A, Li J, Pereira De Siqueira A, Zhang J, Toop HD, Morris JC, et al. Tumor necrosis factor-related apoptosisinducing ligand regulates hallmark features of airways remodeling in allergic airways disease. Am J Resp Cell Mol Biol 2014; 51(1):86-93.

5. Lai T, Chen M, Deng Z, Lü Y, Wu D, Li D, et al. YKL-40 is correlated with FEV1 and the asthma control test (ACT) in asthmatic patients: Influence of treatment. BMC Pulm Med 2015; 15(1). doi: 10.1186/1471-2466-15-1

6. Ulrik CS. Asthma symptoms in obese adults: The challenge of achieving asthma control. Expert Rev Clin Pharmacol 2016; 9(1):5-8.

7. Patadia MO, Murrill LL, Corey J. Asthma. Symptoms and presentation. Otolaryngol Clin North Am 2014; 47(1):23-32.

8. Lautenbacher L, Perzanowski MS. Global asthma burden and poverty in the twenty-first century. Int J Tuberc Lung Dis 2017; 21(11):1093.
9. Soriano JB, Abajobir AA, Abate KH, Abera SF, Agrawal A, Ahmed MB, et al. Global, regional, and national deaths, prevalence, disability-adjusted life years, and years lived with disability for chronic obstructive pulmonary disease and asthma, 1990-2015: a systematic analysis for the Global Burden of Disease Study 2015. Lancet Respir Med 2017; 5(9):691-706.

10. Shuhui L, Mok Y-, Wong WSF. Role of mammalian chitinases in asthma. Int Arch Allergy Immunol 2009; 149(4):369-77.

11. Ashraf M, EhsanUllah, Ahmed M, Zaidi A. Asthma Care Perceptions and Practices Among General Practitioners at Bahawalpur. Pak J Chest Med. 2014; 14:4-7.

12. Khan IM, Arsalan MH, Siddiqui MF, Zeeshan S, Shaukat SS. Spatial Association of Asthma and Vegetation In Karachi: A Gis Perspective. Pak J Bot. 2010; 42:3547-54.

13. Lougheed MD, Leniere C, Ducharme FM, Licskai C, Dell SD, Rowe BH, et al. Canadian Thoracic Society 2012 guideline update: Diagnosis and management of asthma in preschoolers, children and adults: executive summary. Can Respir J 2012; 19(6): $81-88$.

14. Lougheed MD, Lemiere C, Ducharme FM, Licskai C, Dell SD, Rowe BH, et al. Canadian Thoracic Society 2012 guideline update: Diagnosis and management of asthma in preschoolers, children and adults. Can Respir J 2012; 19(2):127-164.

15. Meneghini AC, Paulino ACB, Pereira LP, Vianna EO. Accuracy of spirometry for detection of asthma: A cross-sectional study. Sao Paulo Med J 2017; 135(5):428-33.

16. Latifi $\mathrm{M}$, Khatri S. Is spirometry necessary to diagnose and control asthma? Clevel Clin J Med 2017; 84(8):597-9.

17. Lee SH, Lin CY, Wang PH, Han CP, Yang SF, Chang JT, Lee MC, Lin LY, Lee MS. Significant association of elevated concentration of plasma YKL-40 with disease severity in patients with pelvic inflammatory disease. J Clin Lab Anal. 2012; 26:136-42.

18. Ober C, Tan Z, Sun Y, Possick JD, Pan L, Nicolae R, Radford S, Parry RR, Heinzmann A, Deichmann KA, Lester LA, Gern JE, Lemanske RF Jr, Nicolae DL, Elias JA, Chupp GL. Effect of variation in CHI3L1 on serum YKL-40 level, risk of asthma, and lung function. N Engl J Med. 2008; 358:1682-91.

19. Hounsome N, Fitzsimmons D, Phillips C, Patel A. Developing core economic outcome sets for asthma studies: A protocol for a systematic review. BMJ Open 2017; 7(8). doi: 10.1136/bmjopen-2017-017054

20. Ferkh KE, Nwaru BI, Griffiths C, Patel A, Sheikh A. Healthcare costs of asthma comorbidities: A systematic review protocol. BMJ Open 2017; 7(5). doi: 10.1136/bmjopen-2016-015102.

21. Puig-Junoy J, Pascual-Argenté N. Socioeconomic Costs of Asthma in the European Union, United States and Canada: A Systematic Review. Rev Esp Salud Publica 2017; 91.

22. Saba M, Sharif MR, Akbari H, Nikoueinejad H, and Jolfaii MR. YKL-40 in Asthma and its correlation with different clinical parameters. Iranian J Allerg Asthma Immunol.2014; 13(4):271.

23. Stout JW, Visness CM, Enright P, Lamm C, Shapiro G, Gan VN, Adams GK, Mitchell HE. Classification of asthma severity in children: the contribution of pulmonary function testing. Arch Pediatr Adolesc Med.2006; 160:844-50.

24. Byrne PM, Pedersen S, Lamm CJ, Tan WC, Busse WW. Severe exacerbations and decline in lung function in asthma. 
Syeda Nargis Fatima, Fatima Ali Khan, Jawed Iqbal

Am J Respir Crit Care Med. 2009; 179:19-24.

25. Duru S, Yuce G, Ulasli S, Erdem M, Kizilgun M, Kara F, Ardýc S. The Relationship between Serum YKL-40 Levels and Severity of Asthma. Iran J Allergy Immunol. 2013; 12(3):247-53.

26. Muhammed IA, Diab SM, Soliman DR and Shalaby W. Study of serum YKL-40 in children with bronchial asthma. Egyptian Pediatric Assoc Gazette. 2015; 22:33-35. 